\title{
An Experimental Study on Slotting of Inconel 718 Thin Sheet
}

\author{
Hiroyuki Kodama, Koichi Okuda and Tomoya Hayase \\ Department of Mechanical Systems Engineering, University of Hyogo, Hyogo 671-2280, Japan
}

\begin{abstract}
Many difficult-to-cut materials such as Ni-base super alloy, titanium alloy, and austenite stainless steel which are used extensively in aerospace generally have high strength-to-weight ratios, high corrosion resistance, high strength retention ability at elevated temperatures, and low thermal conductivity. These characteristics can result in uneven tool wear and chatter vibration. Therefore, determining the appropriate end-milling conditions is more difficult for difficult-to-cut materials than for other materials. There has been much research on the high-speed milling of difficult-to-cut materials, and effective end-milling conditions, end-mill tool shapes, and processing methods have been reported. In addition, irregular pitch and lead end-mills with different helix angles have been developed by tool maker's to reduce chatter vibration, making it easier to perform high-speed milling. However, there have been few reports of slotting information useful for determining appropriate end-milling conditions and processing methods for Ni-base super alloy. The aim of this study is to derive end-milling condition with high efficiency grooving process for Ni-base super alloy (Inconel 718) sheet. Effects of cutting parameters were examined from the view point of cutting resistance, tool tip maximum temperature and tool flank wear width. As a result from experiments, if the grooving process condition of axial depth of cut is smaller than other conditions on the same material removable rate value, it has been found that it is possible to reduce the tool tip maximum temperature and prolong the tool life.
\end{abstract}

Key words: Slotting, Ni-base super alloy, thin sheet, end-milling.

\section{Introduction}

Inconel 718, which is a superalloy used in combustors and other components of jet engines, is widely used as sheet stock. Although Inconel 718 has low thermal conductivity and high weldability, however, its high hardness (even at high temperature) makes it difficult to processing. It is thus characterized by extremely poor machinability. As a result, improving the machining efficiency of Inconel 718 is reported to be difficult. On the manufacturing job site, it is a problem that a great deal of time is used up in identifying processing conditions that assure accuracy while each component is actually being processed. Given the above-described circumstances, the need to improve the efficiency and accuracy of machining (i.e., end-milling) of Inconel 718 is growing $[1,2]$. Accordingly, studies on cutting/machining of Inconel

Corresponding author: Hiroyuki Kodama, research associate, Dr. Eng., research fields: end-milling, data-mining, and difficult-to-cut materials.
718 are ongoing. A lot of those studies, however, have looked into cutting speed $[3,4]$. And most studies using end-mills have focused on side milling; in contrast, studies on groove machining are few and far between [5]. As for MRR (material removal rate), which expresses machining efficiency, three cutting parameters - namely, spindle rotation speed, feed rate per tooth, and axial cutting depth - are closely related $[6,7]$. Accordingly, by investigating the effect of each parameter on cutting resistance and cutting temperature, it is possible to select the cutting parameters that can lower cutting resistance and cutting temperature while keeping the same MRR.

In the present study, which aimed to improve machining efficiency of Inconel 718, milling of a thin sheet of Inconel 718 - assumed to be a typical process for manufacturing aircraft components-was performed. In particular, Inconel 718 was subjected to groove machining ("grooving" hereafter), the effects of the three above-mentioned cutting parameters (i.e., 
spindle rotation speed, feed rate per cut, and axial cutting depth) on cutting force and tool-cutting-edge temperature were experimentally investigated, and guidelines for selecting the cutting parameters so as to suppress the tool temperature while keeping MRR constant were established.

\section{Experimental Method}

The machine tool used in the experimental investigation was a TV-30 tapping center of DMG MORI SEIKI Co., Ltd. A holder (BT30, NT Tool Corporation) with a spring collet, were mounted on the main spindle axis, and the end-mill overhang length was kept to $30 \mathrm{~mm}$. The end-mill tool (Sumitomo Electric Hardmetal Division) had four flutes and a helical angle of $45^{\circ}$. The work material used was a superalloy commonly used for components of aircraft engines, namely, Inconel 718, with dimensions of $50 \times 40 \times 5 \mathrm{~mm}$. For measuring cutting resistance, a three-component force transducer (KISTLER 9378B) was used. Water-soluble cutting oil was used for wet processing. Moreover, to investigate variation in tool temperature due to difference in cutting parameters, infrared thermography (NEC Avio Infrared Technologies Co., Ltd.) was used, and the cutting temperature during grooving was measured. The experimental setup is shown in Fig. 1. The range captured by the thermograph covers the interval from the cutting edge finishing the down cut (at tool rotation angle $\theta=\pi$, defined in the figure) to starting the up cut (at $\theta=0$ ). Moreover,

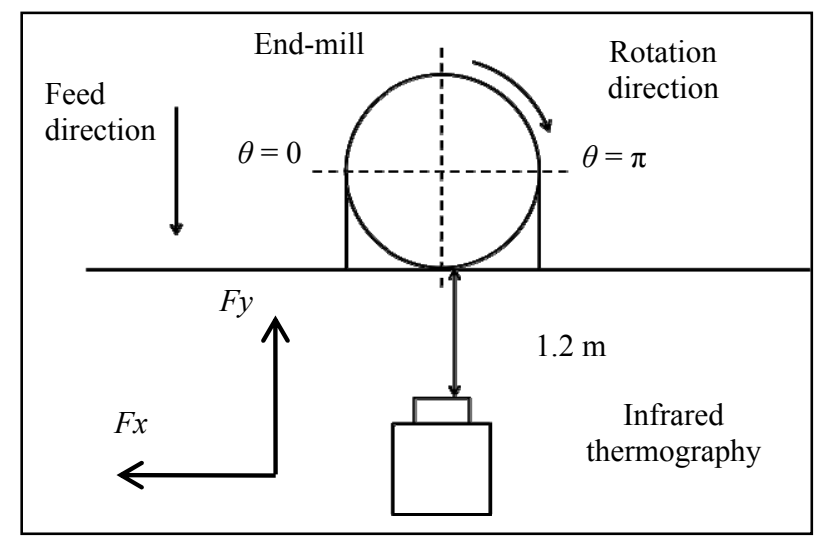

Fig. 1 Experimental setup for milling temperature measurement. during wet processing, oil solution blocks the tool from the thermography camera, so it is difficult to capture thermal images. Accordingly, during the measurement of cutting temperature, vegetable-containing oil, BLUEBE LB-1 (FUJI-BC ENGINEERING), was supplied as the oil solution.

\section{Experimental Results and Discussion}

\subsection{Evaluation of the Effect of Cutting Parameters by Using Design of Experiments}

To evaluate the effect of each cutting parameter on cutting resistance, it is necessary to vary cutting parameters under determined conditions, and estimate them by carrying out experimental tests. In the present study, the experimental conditions were determined byusing the "design of experiments" method. In the case of grooving, three cutting parameters, namely, principle-axis rotation (spindle) speed $S$ (rpm), feed rate per tooth $f(\mathrm{~mm} /$ tooth $)$, and axial depth of cut $A d$ $(\mathrm{mm})$, are key factors. In reference to the conditions specified in the catalog of the tool used, the standard values for these factors were set as $S=1,200 \mathrm{rpm}$, $f=0.035 \mathrm{~mm} /$ tooth, and $A d=1.2 \mathrm{~mm}$. Moreover, in reference to the know-how of operators on-site, these parameters were supposed as the upper limits at which "chipping" and significant wear develop in one processing pass (i.e., cutting distance of $40 \mathrm{~mm}$ ), and values that fell below similar standard values were taken as three standard lower limits. And the experimental conditions were set as listed in Table 1 according to a Latin-square design.

Table 1 Cutting conditions.

\begin{tabular}{lllll}
\hline Test & $S(\mathrm{rpm})$ & $F(\mathrm{~mm} /$ tooth $)$ & $A d(\mathrm{~mm})$ & $M R R\left(\mathrm{~cm}^{3} / \mathrm{min}\right)$ \\
\hline 1 & 800 & 0.020 & 0.5 & 0.26 \\
2 & 800 & 0.035 & 1.2 & 1.08 \\
3 & 800 & 0.050 & 2.0 & 2.56 \\
4 & 1,200 & 0.020 & 1.2 & 0.92 \\
5 & 1,200 & 0.035 & 2.0 & 2.69 \\
6 & 1,200 & 0.050 & 0.5 & 0.96 \\
7 & 1,600 & 0.020 & 2.0 & 2.05 \\
8 & 1,600 & 0.035 & 0.5 & 0.90 \\
9 & 1,600 & 0.050 & 1.2 & 3.08 \\
\hline
\end{tabular}


The relationship between MRR and cutting resistance is shown in Fig. 2. Although MRR and cutting resistance are proportional, in the case of MRR of more than $2.5 \mathrm{~cm}^{3} / \mathrm{min}$, it can be seen that cutting resistance starts to fall. Moreover, by comparing the three results obtained under the condition that MRR was in the range of 0.90 to $0.96 \mathrm{~cm}^{3} / \mathrm{min}$, it can be seen that both $F x$ and $F y$ cover a cutting-resistance range of about $60 \mathrm{~N}$.

Here, to derive appropriate cutting conditions that provide low cutting resistance while maintaining high MRR, S/N (signal-to-noise) ratio corresponding to each cutting parameter was obtained from the results shown in Fig. 2, and a factor-evaluation diagram was constructed. Since it was desired to suppress cutting resistance, characteristics referred to as "smaller-the-better" (namely, small values are defined as preferable) were used. Drawn up on the basis of the experimental results shown in Fig. 2, a

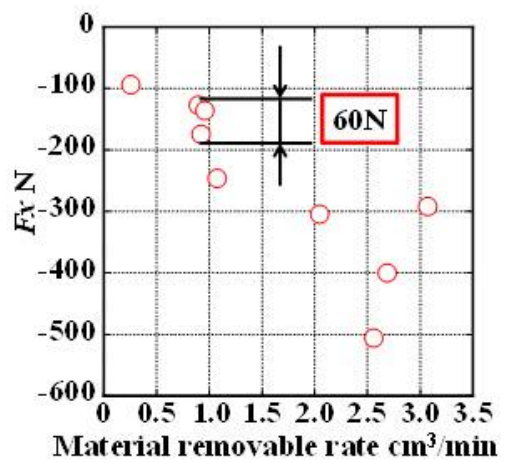

cause-and-effect diagram concerning cutting resistance in each direction ( $F x$ and $F y)$ is shown in Fig. 3. It is clear from this figure that with respect to $S, \mathrm{~S} / \mathrm{N}$ ratio shows pretty marginal change and has little effect on cutting resistance. In regard to $f$ and $A d$, in contrast, it is clear that $\mathrm{S} / \mathrm{N}$ ratio decreases as the set values increase. These results indicate that cutting resistance is increased when either $f$ or $A d$ are increased. Moreover, when the trends in $\mathrm{S} / \mathrm{N}$ ratio for the three parameters are compared, it becomes clear that the trend in $\mathrm{S} / \mathrm{N}$ ratio for $A d$ is more pronounced than the trends in $\mathrm{S} / \mathrm{N}$ ratio for the other two parameters. It can thus be said that the magnitude of $A d$ is strongly related to the increase and decrease of cutting resistance. It is concluded from the above-described results that by making $A d$ (which has the most significant effect on the increase and decrease in cutting force) small, it is possible to lower cutting resistance, while keeping MRR constant, by increasing either $f$ or $S$.

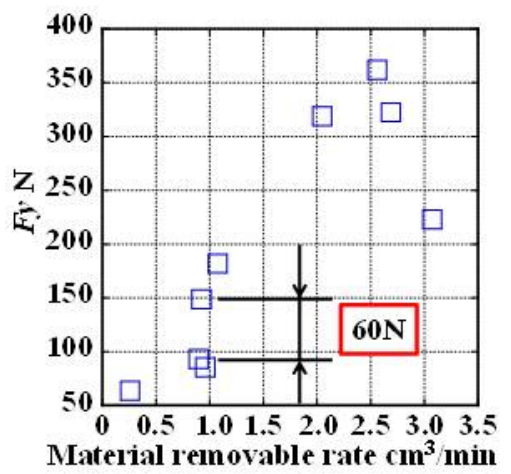

Fig. 2 Relationship between $M R R$ and cutting force.

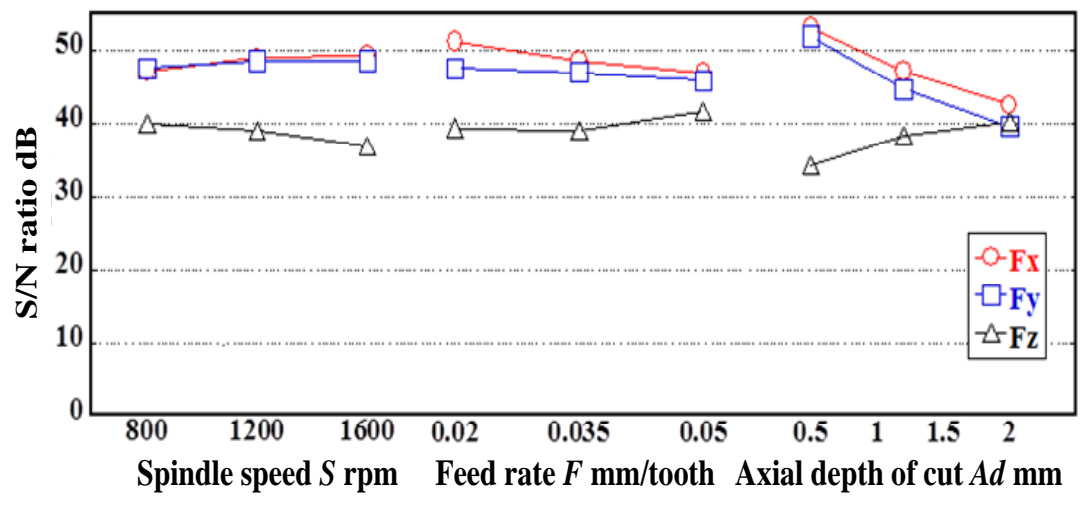

Fig. 3 Cause-and-effect diagram. 


\subsection{Relationship between Positional Aberration at the End of the Groove and Cutting Resistance}

The occurrence of a positional aberration at the end of a machined groove (as shown in Fig. 4) was ascertained. In regard to that aberration, it was reported by Masuda et al. that the positional aberration of the groove occurs as a result of the tool being elastically deformed during cutting (with a minute end-mill with two blades) and recovering from that elastic deformation at the termination of the processing [8]. As a result of that phenomenon, if the cutting resistance is increased, the elastic deformation of the tool is increased, and the positional aberration of the groove gets larger. Accordingly, the positional aberration of the groove at the termination of cutting under nine conditions was plotted against MRR and compared to changes in resultant force corresponding to cutting resistance. As shown in Fig. 5, the increase and decrease in the positional aberration of the groove at the termination of cutting is in accord with those of resultant forces $F x$ and $F y$ corresponding to cutting resistances occurring during processing. In other words, suppressing the cutting resistance occurring during grooving of Inconel 718 reduces the elastic deformation of the tool generated during processing and makes it possible to lower the amount of positional aberration at the termination of the groove.

\subsection{Effect of Difference in Cutting Parameters on Cutting Temperature}

As representatives examples of the experimental

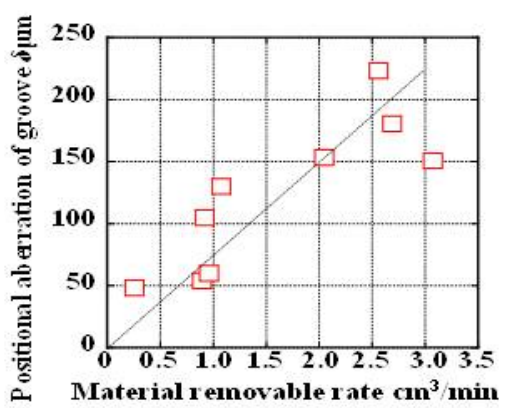

conditions mentioned in Section 3.1, the conditions under which cutting force is a minimum - in addition to the conditions under which values of $F x$ and $F y$ are maximum, average, and minimum-were selected from the cause-and-effect diagram, and temperature-measurement tests were carried out under these conditions. The experimental conditions are listed in Table 2. The relationship between MRR and tool temperature is plotted in Fig. 6. The graph shows a clear trend in which tool temperature increases as MRR increases. However, when the results of tests 4 and 5 (which show similar MRR values of 0.92 and $0.90 \mathrm{~cm}^{3} / \mathrm{min}$, respectively) are compared, it is clear that maximum tool temperatures become high, and the difference between the two temperatures is more than $100{ }^{\circ} \mathrm{C}$. Furthermore, it is clear that the maximum tool temperature obtained by test 2 (with a higher MRR) decreases. As for tests 2, 4, and 5 (with similar MRR values), time variation of cutting temperature is shown in Fig. 7. In the case of high feed rate, it is possible that processing will finish

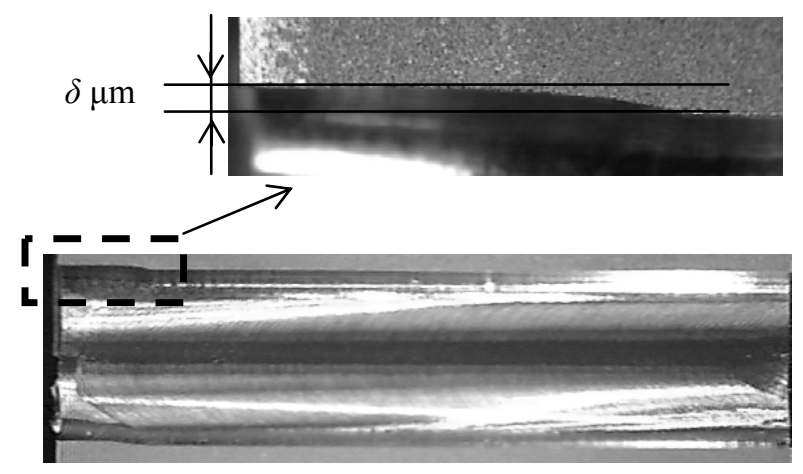

Fig. 4 Positional aberration of groove.

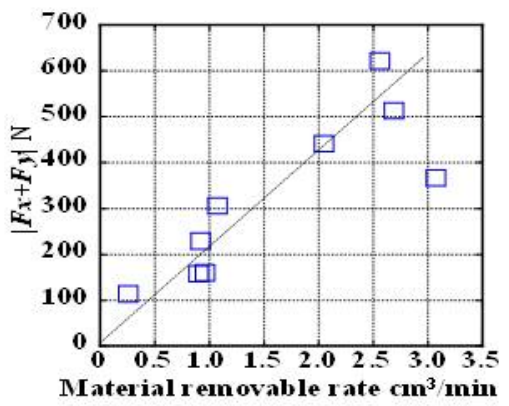

Fig. 5 Relationship between MRR and positional aberration of groove, and relationship between MRR and resultant cutting force. 
Table 2 Cutting conditions.

\begin{tabular}{lllll}
\hline Test & $\begin{array}{l}S \\
(\mathrm{rpm})\end{array}$ & $\begin{array}{l}f \\
(\mathrm{~mm} / \text { tooth })\end{array}$ & $\begin{array}{l}A d \\
(\mathrm{~mm})\end{array}$ & $\begin{array}{l}\text { MRR } \\
\left(\mathrm{cm}^{3} / \mathrm{min}\right)\end{array}$ \\
\hline 1 & 800 & 0.020 & 0.5 & 0.26 \\
2 & 800 & 0.035 & 1.2 & 1.08 \\
3 & 800 & 0.050 & 2.0 & 2.56 \\
4 & 1,200 & 0.020 & 1.2 & 0.92 \\
5 & 1,600 & 0.035 & 0.5 & 0.90 \\
6 & 1,600 & 0.020 & 0.5 & 0.52 \\
\hline
\end{tabular}

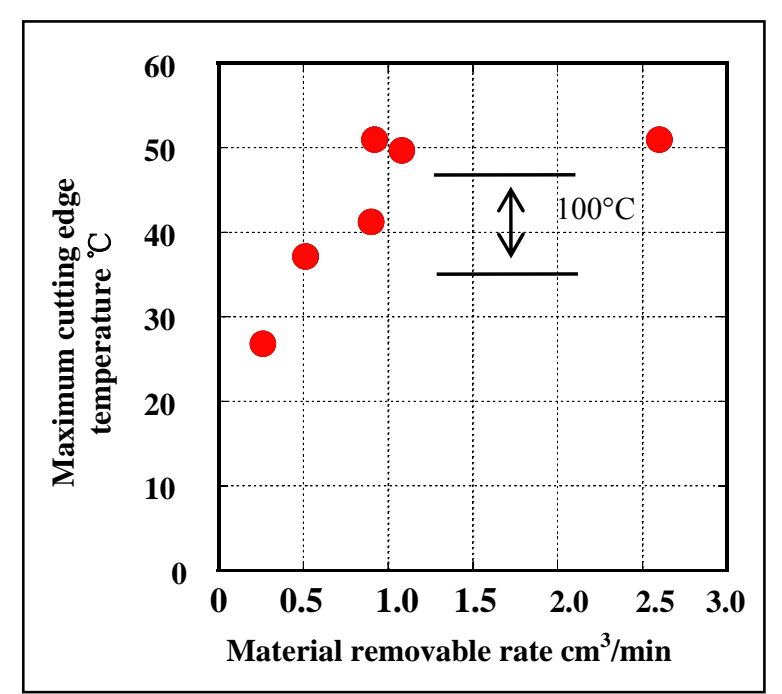

Fig. 6 Relationship between MRR and tool maximum cutting edge temperature.

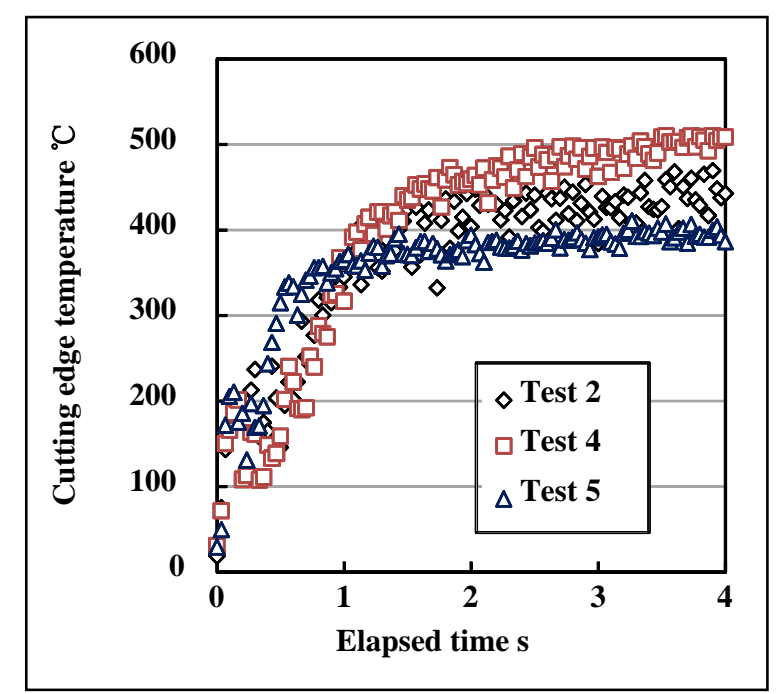

Fig. 7 Relationship between elapsed time and tool temperature.

before the cutting temperature rises to convergence and that the cutting temperature will show a low value. However, it is clear from Fig. 7 that even under the condition that the cutting temperature is low, the cutting temperature converges. In light of the above-described results, it is considered that it is possible to lower the increase in tool temperature, while keeping the same MRR, by changing the way of capturing the cutting parameters.

The cause of the difference in maximum tool temperatures was investigated by using thermal images taken during tests 4 and 5. As for differences between the conditions of these two tests, in test 4, when $S$ and $f$ were controlled, $A d$ was increased. On the contrary, in test 5, when $A d$ was controlled, $S$ and $f$ were increased.

Thermal images taken during tests 4 and 5 are shown in Fig. 8. These images were taken at the four-second point shown in Fig. 7 (i.e., after the grooving had progressed to raise the tool temperature sufficiently). Under either condition, the maximum tool temperature occurs at the section corresponding to the axial cutting depth of the tool's cutting edge, and the temperature at the boundary (i.e., not at the tip of the tool) is the highest temperature.

Comparing the two images shows that the region in which the tool temperature is close to the maximum is bigger in the case of test 4 than in the case of test 5 .

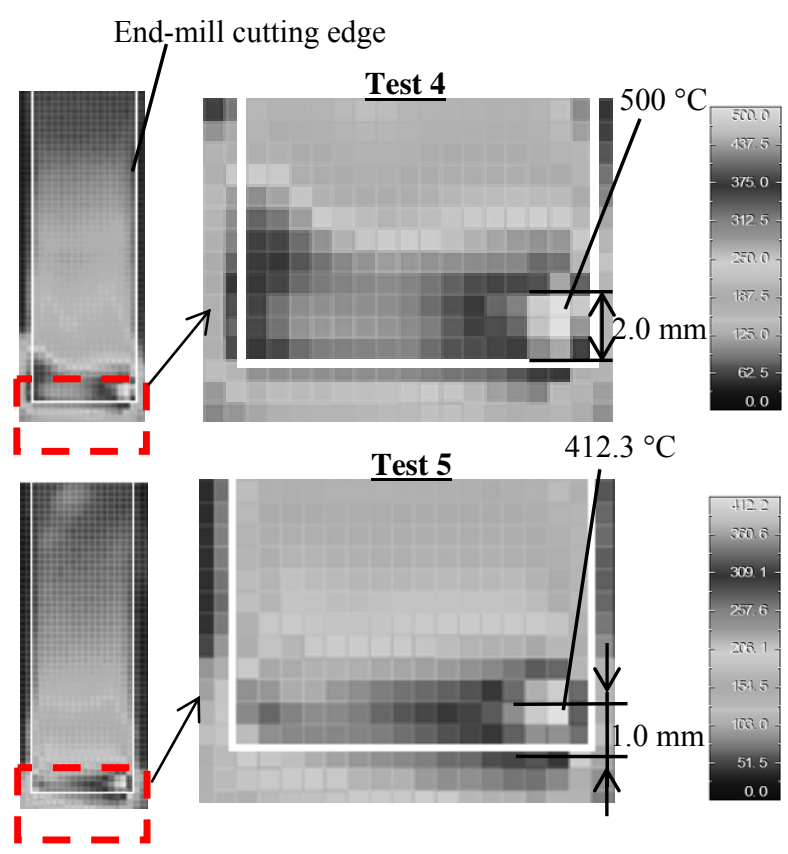

Fig. 8 Thermal images concerning test runs 4 and 5. 
The images confirm that the length of the heat source changes in accordance with $A d$; namely, it is about 2.0 $\mathrm{mm}$ in the case of test 4 and about $1.0 \mathrm{~mm}$ in the case of test 4. It is thus considered that when the heat-source length increases, the amount of inputted heat increases, and the tool temperature rises accordingly.

Furthermore, comparing tests 2 and 4 shows that in spite that MRR is higher in test 2, the tool's cutting-edge temperature is lower than that in test 4 . In those tests, the values of $A d$ are the same, but in test 2, grooving was performed with low spindle revolution rate $(S)$ and high feed rate $(f)$, and in test 4 , grooving was performed at high $S$ and low $f$. It is therefore concluded that $S$ has a greater effect on the rise in tool temperature than $f$. The above-described findings reveal that in regard to grooving of Inconel 718, under a certain condition, it is possible to lower the maximum tool temperature by reducing $A d$ and increasing $f$ while keeping MRR constant.

\subsection{Experimental Results on Tool Wear}

The results concerning wear of the flank face of the tool obtained in tests 4 and 5 are shown in Fig. 9. Although the values of $M R R$ are pretty much the same under these two test conditions, the processing times differ, even in an equivalent single pass of the grooving process, because the feed rates differ. In test 5 , processing time for one pass is $11.8 \mathrm{~s}$, while in test 4, it is $15.7 \mathrm{~s}$. As a result, in each test, the volume of material removed in a single pass differs. Given that fact, the time taken for a single pass was calculated, and the volume of material removed was estimated. Moreover, the states of wear on the flank face of the tool under a condition that gives similar amounts of material removed in the two tests were compared. Observations of the flank face are shown in Fig. 10. The values of the amounts of material removed are written as $V\left(\mathrm{~cm}^{3}\right)$ below each image.

Under either condition, it is clear that the maximum amount of wear develops at the boundary corresponding

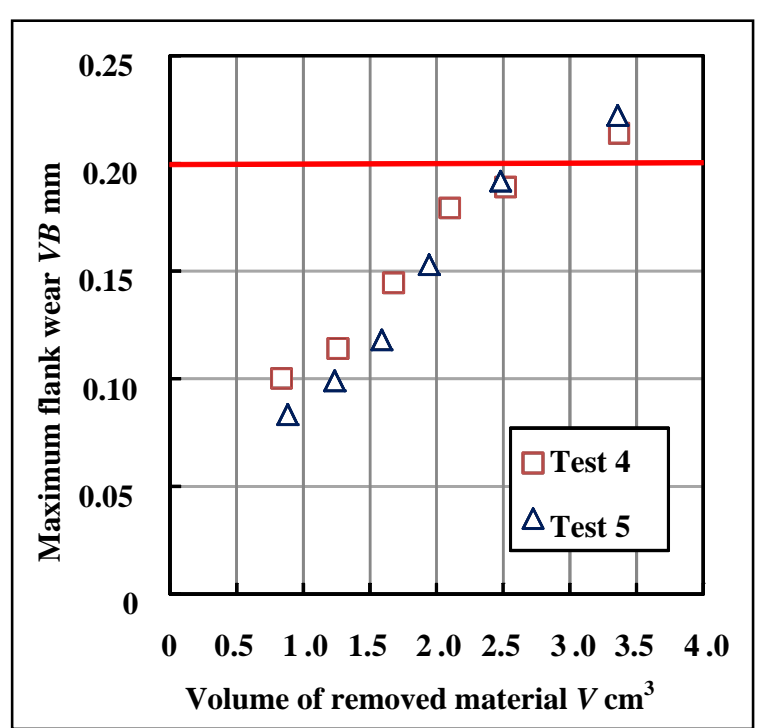

Fig. 9 Relationship between volume of removed material and wear.

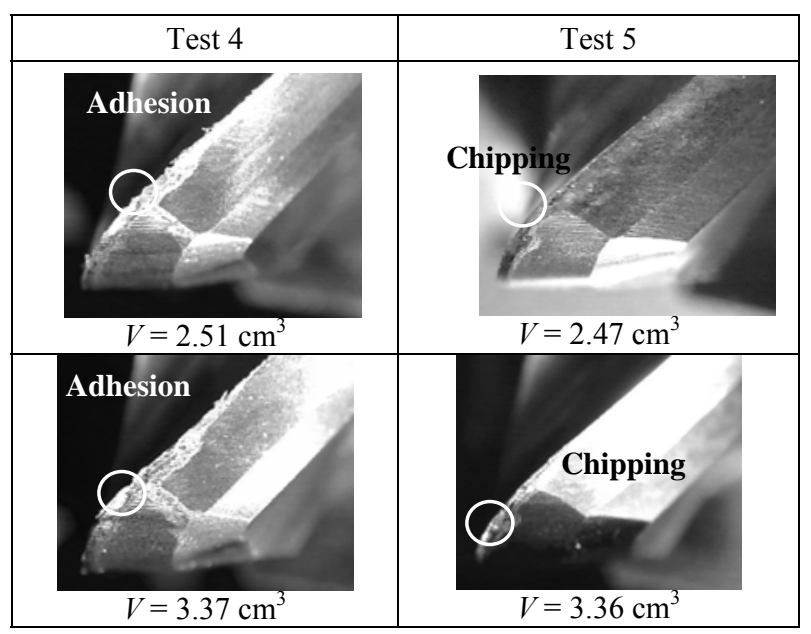

Fig. 10 Observation results of flank face.

to the axial depth of cut in accordance with the increasing amount of material removed. It is clear that in test 5 , so-called "chipping" occurs at the boundary in the case that $V$ is about $2.5 \mathrm{~cm}^{3}$. After that, the section including chipping gets expands as wear progresses. As a result, the eventual wear width in test 5 exceeds that in test 4 . However, outside the section containing the chipping, the wear width in test 5 is smaller. On the contrary, in test 4 , the wear on the whole cutting edge (centered on the region around the boundary) progresses substantially, and at $V=2.51$ $\mathrm{cm}^{3}$ and above, adhesion can be seen.

According to the results reported up until this point, 
both cutting resistance and tool temperature are higher in test 4. It is thus considered that wear progresses more rapidly in test 4 because the higher temperature and higher load. The chipping observed in test 5 is considered to be caused by the axial cutting depth being small and the temperature of the part of the cutting edge with low strength becoming high. From the results presented above, it is clear that from the viewpoint of wear, if the amount of material removed is kept constant, it is effective to set the processing conditions such that $A d$ is controlled.

3.5 Variation of Surface Roughness in Accordance with Difference in Fixation Methods for the Work Material

The method used to fix the thin Inconel 718 sheet was changed, and the processed sheet was observed. "Jig 1" is the fixation method used in the tests described so far, and "Jig 2" is the method use to hold a thin sheet in mid-air. The test conditions are those for tests 1 to 3 listed in Table 2. Curved lines indicating the roughness of the bottom surface of the thin sheet fixed by each jig are shown in Fig. 11. The figure reveals two key findings. First, looking at the roughness line in the case of Jig 1 reveals a series of bumps in the line. In regard to grooving with a small-diameter end-mill, it has been reported that when the tool is deflected, a bumpy shape is formed on the bottom surface of the processed sheet as a result of transferring the outline of the slanted tool [9], and the same phenomenon was confirmed by the results of the present experimental tests.

Next, looking at the roughness line in the case that Jig 2 was used in both tests 1 and 2 reveals that $\mathrm{Ra}$ is reduced by about $50 \%$ compared to when Jig 1 was used. FFT (fast Fourier transform) results (acceleration data in the z-direction) when both jigs were used in test 1 are shown in Fig. 12. In the case of either jig, peaks appear near $50 \mathrm{~Hz}$. These peaks are considered to be due to vibration caused by the cutting force that corresponds to the period in which the blade of the

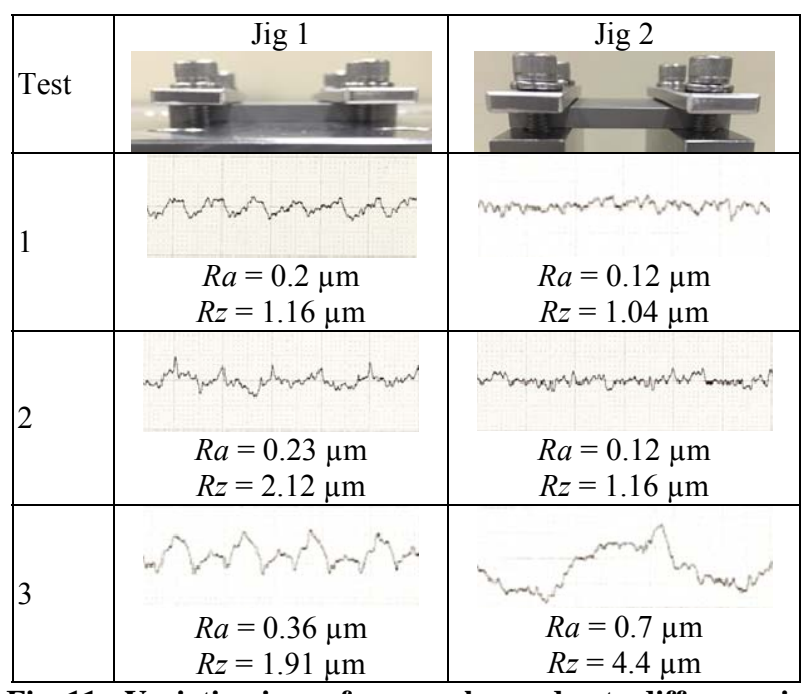

Fig. 11 Variation in surface roughness due to difference in fixation methods.

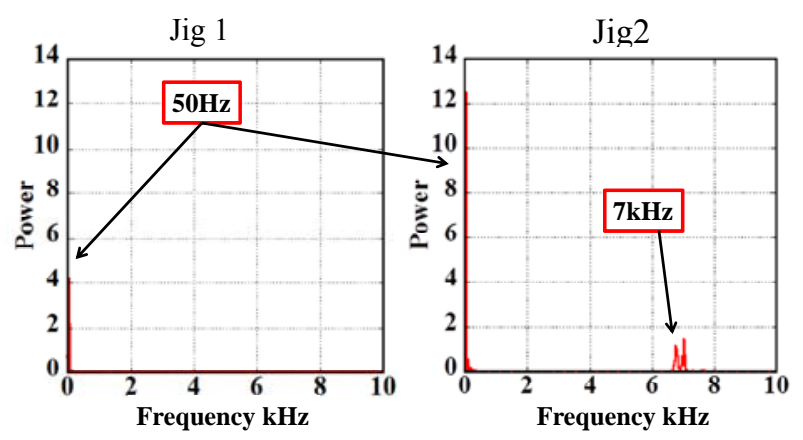

Fig. 12 FFT results for each jigs.

end mill is touching the work material. Moreover, it is clear that in the case Jig 2 was used, peaks also occur near a frequency of $7 \mathrm{kHz}$. It can thus be said that the roughness is reduced by minute vibrations of the work material in the z-direction during processing. The results of test 3 indicate that the roughness is increased when Jig 2 is used. This result is explained by the fact that the roughness of the processed surface is increased by chattering of the work material (as confirmed by observing chatter marks on the processed surface.

\section{Conclusions}

In this study, grooving of Inconel 718 thin sheet was performed by using an end mill, and the effects of cutting parameters on cutting resistance, tool temperature, and precision of grooving were 
investigated. The three key results of this investigation are summarized as follows. First, according to a cause and effect diagram, $A d$ (axial depth of cut) has the greatest effect on the increase in cutting resistance. In other words, it is possible to lower the cutting resistance by controlling $A d$ to keep the amount of material removed the same while selecting the processing conditions so that $S$ (spindle speed) and $f$ (feed rate per tooth) are large. Second, by comparing the results of temperature-measurement tests (namely test 4 and 5), the length of the high-temperature region considered to be the heat source can be shortened by controlling $A d$ to keep the same MRR. Third, average surface roughness $(R a)$ can be reduced by $50 \%$ by fixing the thin sheet in a mid-air manner.

\section{References}

[1] Kasim, M. S., Che Haron, C. H., Ghani, J. A., Seadon, J. B., and Sulaiman, M. A. 2014. "Cutting Performances of Coated PVD in High Speed End Milling of Aged Inconel 718." Materials Science Forum 773-774: 661-8.

[2] Alauddin, M., El Baradie, M. A., and Hashmi, M. S. J. 1996. "Optimization of Surface Finish in End Milling Inconel 718." Journal of Materials Processing Technology 56: 54-65.

[3] Itakura, K., Kuroda, M., Doi, Y., Tsukamoto, H., and Ariura, Y. 2000. "High Speed Cutting of Super Heat
Resisting Alloy Inconel 718 on the Finish Cutting with High Pressurized Cutting Fluid." Journal of Japan Society for Precision Engineering 66: 1611-5.

[4] Yatsuzaki, T., and Onikura, H. 2005. "The Effect of Oil-Mist Application on the Machinability in Turning of Super Heat-Resistant Alloy Inconel 718." Journal of Japan Society for Precision Engineering 71: 1377-82.

[5] Sekiya, K., Yamane, Y., and Narutaki, N. 2004. "Tool Wear under High Speed End Milling of Nickel-base Superalloy Inconel 718." Journal of Japan Society for Precision Engineering 70: 1086-90.

[6] Kodama, H., Hirogaki, T., Aoyama, E., and Ogawa, K. 2011. "Aid of End-Milling Condition Decision Using Data Mining from Tool Catalog Data for Rough Processing." Advanced Materials Research 325: 345-50.

[7] Kodama, H., Hirogaki, T., Aoyama, E., Ogawa, K., and Okuda, K. 2014. "Experimental Verification of End-Milling Condition Decision Support System Using Data-Mining for Difficult-to-Cut Materials." Advanced Materials Research 1017: 334-9.

[8] Masuda, M., Ai, J., Horiuchi, O., Shibata, T., Nomura, M., and Murakami, Y. 2013. "Investigation of Geometric Groove Accuracy in Micro End Milling (1st Report) - Groove Position Error and Groove Warp in Tool-Width Milling-." Journal of Japan Society for Precision Engineering 79: 176-81.

[9] Kamidaki, Y., Morita, N., Yamada, S., Takano, N., and Sekiguchi, T. 2012. "Research on the Vector of Milling Force and Cutting Phenomena in Micro End Milling." In Proceedings of Japan Society for Precision Engineering, 163-4. 